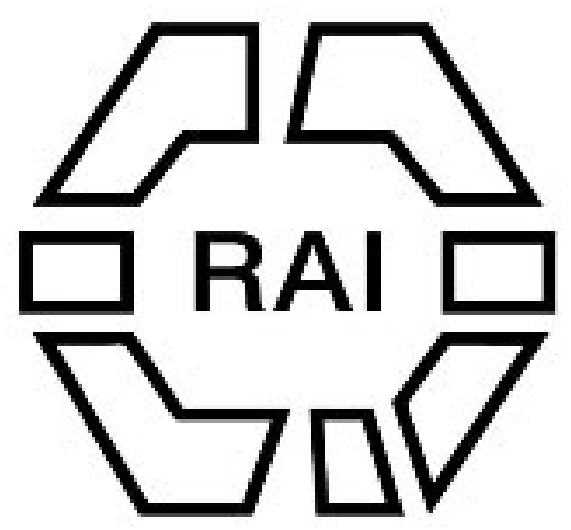

On a Rare Fabric of Kabyle Pottery

Author(s): D. Randall-MacIver

Source: The Journal of the Anthropological Institute of Great Britain and Ireland, Vol. 32

(Jan. - Jun., 1902), pp. 245-247

Published by: Royal Anthropological Institute of Great Britain and Ireland

Stable URL: http://www.jstor.org/stable/2842916

Accessed: 14/06/2014 08:06

Your use of the JSTOR archive indicates your acceptance of the Terms \& Conditions of Use, available at http://www.jstor.org/page/info/about/policies/terms.jsp

JSTOR is a not-for-profit service that helps scholars, researchers, and students discover, use, and build upon a wide range of content in a trusted digital archive. We use information technology and tools to increase productivity and facilitate new forms of scholarship. For more information about JSTOR, please contact support@jstor.org. 


\section{ON A RARE FABRIC OF KABYLE POTTERY.}

By D. Randall-Maciver, M.A.

[With Plates XVIII, XIX, $c f$. Plate XX.]

IN a paper which was read before the Institute some eighteen months ago, I had occasion to treat at some length of the subject of Kabyle pottery. The various types were then classified for purposes of description under six headings, viz.:(1) Pots with white or light yellow decoration on a red ground. (2) With red decoration on a white ground. (3) With black decoration on a white ground. (4) Red ware with very little ornamentation. (5) Pottery with black decoration on a yellow ground. (6) Plain pottery without any painted decoration.

It was pointed out that the third of these classes is of peculiar interest from the circumstance that it is identical in respect both of technique and of ornamentation with certain Cypriote ware which may be dated to about 900 B.C.

At the time of presenting the paper in question, I was able to describe only such few specimens of this rare black-and-white pottery as had been brought back from Algeria by the late Mr. Anthony Wilkin and myself. Within the last few months, however, I have been given the opportunity of studying the unique private collection belonging to the lady who presented to the British Museum the fine examples which it possesses; and it has seemed worth while to publish together in one place a representative group of the entire series.

Accordingly, in Plates XVIII and XIX are shown twenty-one examples; which, with the exception of those numbered as $2,7,11,15$, are reproduced on a uniform scale of $\frac{2}{15}$ th natural size. The four which are on a slightly larger scale are in the British Museum; No. 2 is 10 inches high, No. 7 and No. 11 are $9 \frac{1}{2}$ inches high, and the bowl figured as No. $15^{1}$ is about 8 inches wide. For the photographs of these four specimens I am indebted to the courtesy of the officials of the Ethnological Department..

Nos. 5, 6, 8, 9, 10,12,13, 14 were collected by my fellow traveller and myself in Algeria and are now in the Pitt-Rivers Museum at Oxford. The remaining examples are taken from the private collection already mentioned, to the owner of which my cordial thanks are due for the permission given me to study and to photograph them.

These pots, which, it will be noticed, are of very various forms and dimensions, are characterized by a simple scheme of rectilinear ornament painted in black upon a brilliant white background, that in the best examples has the appearance of a hard slip. Whether it can properly be described as a slip must depend upon the exact connotation, as yet scarcely established, which is to be assigned to that term. Unfortunately we did not in our travels come upon the seat of the manufacture, which is said to be in the neighbourhood of Toudja, on the north-eastern borders of Algeria. Consequently, I am unable as yet to describe the full process from ocular observation; but an examination of the various specimens figured in the illustrations makes it possible to ascertain the essential features. Thus it is evident, for in-

1 The decoration of No. 15 is painted in dull red instead of black; but this seems to be an accidental variation, and the pot is otherwise identical in character with the others which are described. 
stance, that the white surface has not been produced by dipping the vase into a finely levigated clay, as in the process generally adopted with what is called "slip" ware. For in many cases the white has overlapped on to the inner surface of the vessel in a way which could only occur if it was laid on as a thick wash by means of a brush.

The treatment therefore of the black and white ware, ${ }^{1}$ as also that of the reddecorated white ware of Class 2 , must have been the same as that which we actually saw practised at Tagamunt-Azuz and at other places where the commoner classes of pottery were manufactured. That is to say, the woman-potter, having fashioned the vase or bowl in the coarse rose-coloured clay of the country, leaves it on one side until such time as it is fully dried. Then she moistens the surface with water and burnishes it with a pebble until it is smooth enough to receive the paint. The pigments are obtained from raw native earths; the white is a marl containing 70 per cent. of silica with 18.5 per cent. of alumina, while the black is an iron ore containing 88.4 per cent. of ferric oxide. First the white is applied as a heavy wash with a very broad brush, and then the patterns are painted upon it with fine brushes of graduated thickness.

Unlike the better known varieties of Kabyle pottery, and unlike our Class 2, the black and white ware does not receive a final varnishing with yellow resin. The background consequently retains its pure whiteness, with a smooth hard surface which is no doubt produced by pebble-burnishing. The red $L \hat{u} k$ is, however, sometimes used to fill in blank spaces (e.g. in Nos. 8, 9, 10, 12, 13, 14).

The patterns are of peculiar interest; how closely they are identical with those of the Cypriote pottery will be shown by Mr. J. L. Myres in his accompanying paper (p. 248). They are all of rigidly rectilinear motive, and, in spite of cursive degradations, can be shown to be composed of only three elements, viz. :-(1) the Triangle, (2) the Lozenge, and (3) the Band (Plate XX).

(1) The triangle is in its simplest form an open zigzag, as shown in 21, of which Plate XIX affords a good example.

Solid triangles, filled in with black, are commoner and occur very frequently in one combination or another. In 24 they are arranged consecutively on the same side of a horizontal line, in 26 they are alternated on either side of the line, and from 26 by a process of cursive degeneration are evolved 15, 16, 17, 23, 24, and 25 . The triangles are at first carefully drawn, but with careless execution the original form is quickly lost, so that the dog-tooth becomes a mere scrabble, and the scrabble s ultimately transformed into a regular cross-barred line (25). The latticed triangle (44) is not less common than the solid triangle, and may be observed on Plate XVIII, 14 and 15.

(2) The lozenge, which appears everywhere in this ornamentation, is apparently derived from the juxtaposition of triangles. It is the most frequent of all motives throughout Kabyle work. Very commonly alternated with the triangle on the same piece, it may similarly be open, solid, or latticed $(37,44,50)$. Of the

1 Mrs. Eustace Smith has lately presented the Pitt Rivers Museum at Oxford with two very fine specimens of the Toudja series. 
Journal of the Anthropological Institute, Vol. XXXII, Plate XVIII.

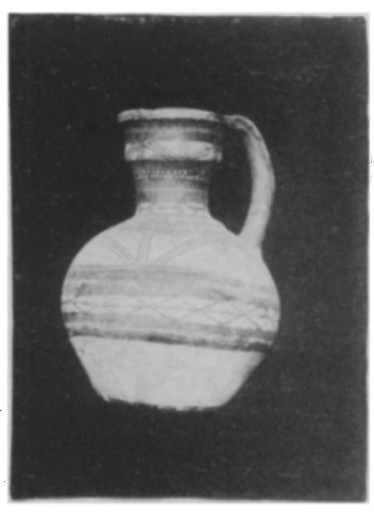

1

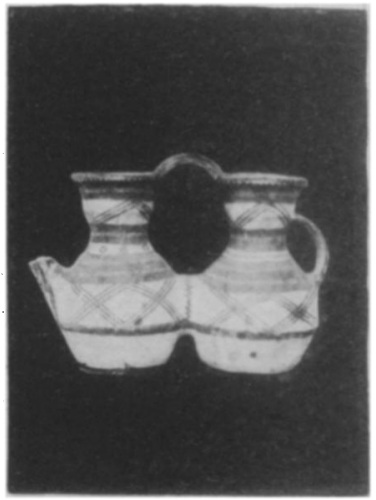

4

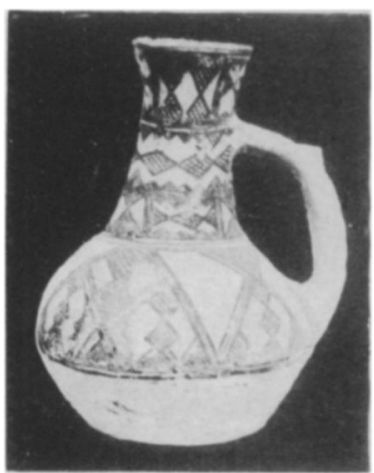

7

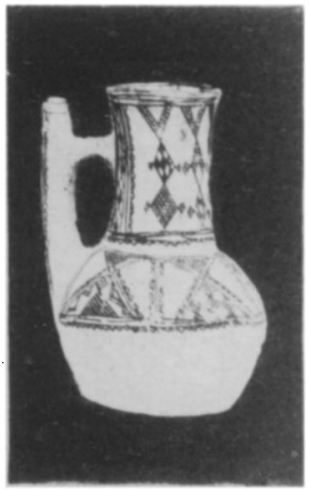

11

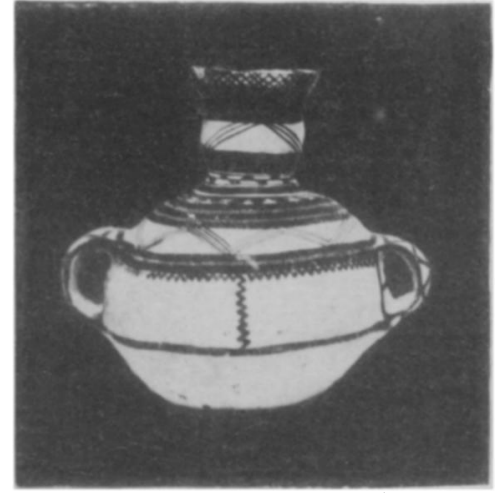

2

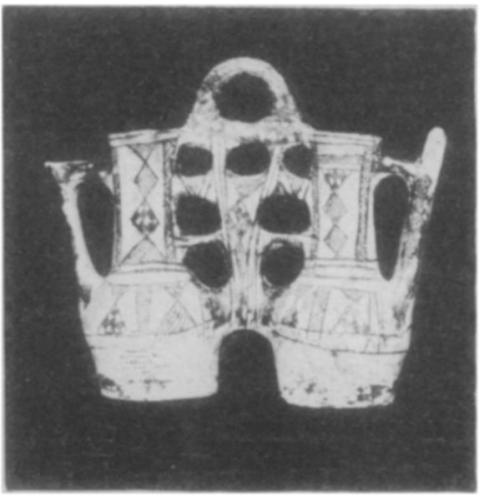

$\mathbf{5}$

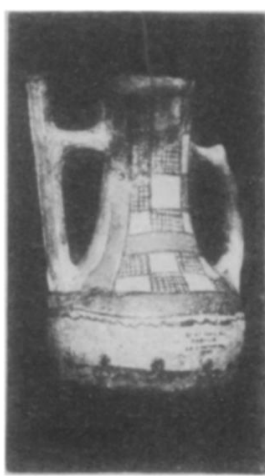

8

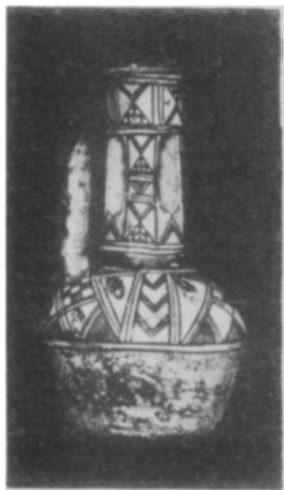

12

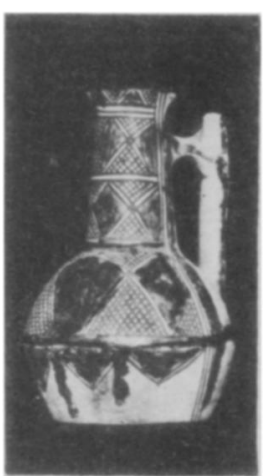

$\boldsymbol{9}$

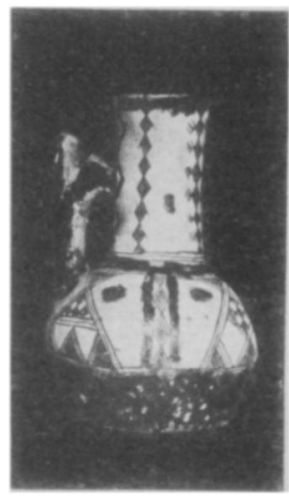

13

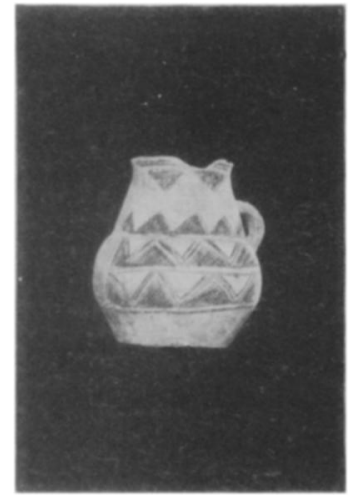

8

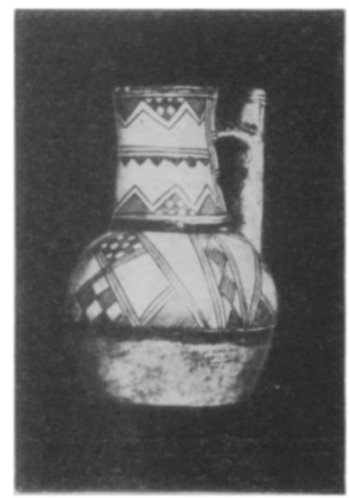

6

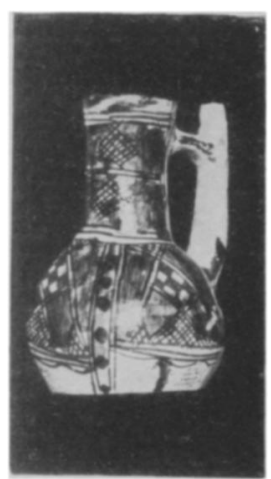

10

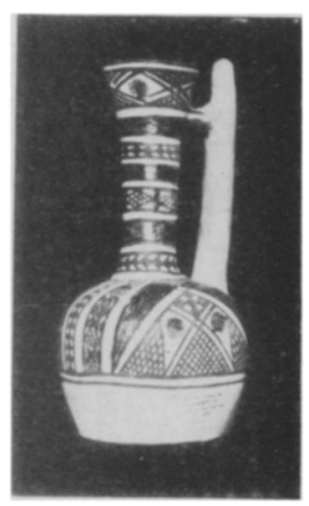

14

KABYLE POTTERY. 


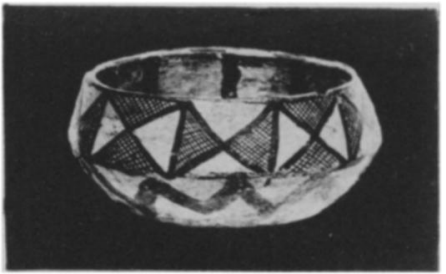

15

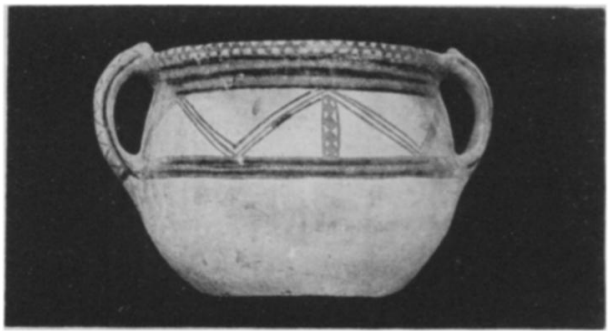

16

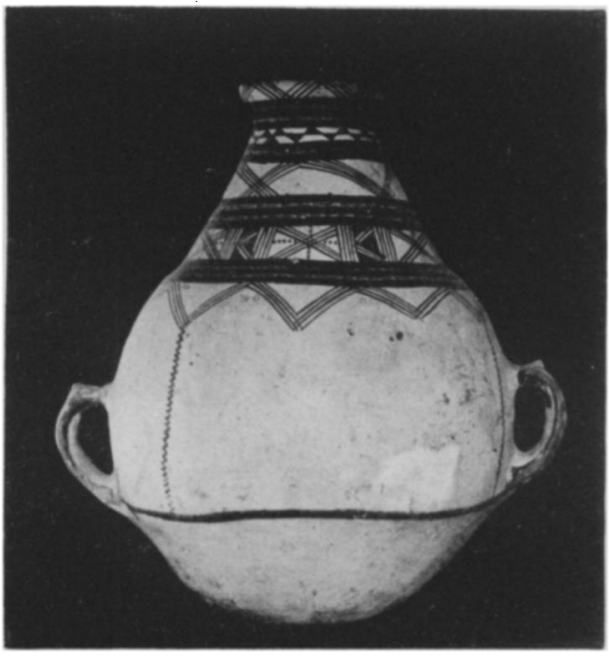

18

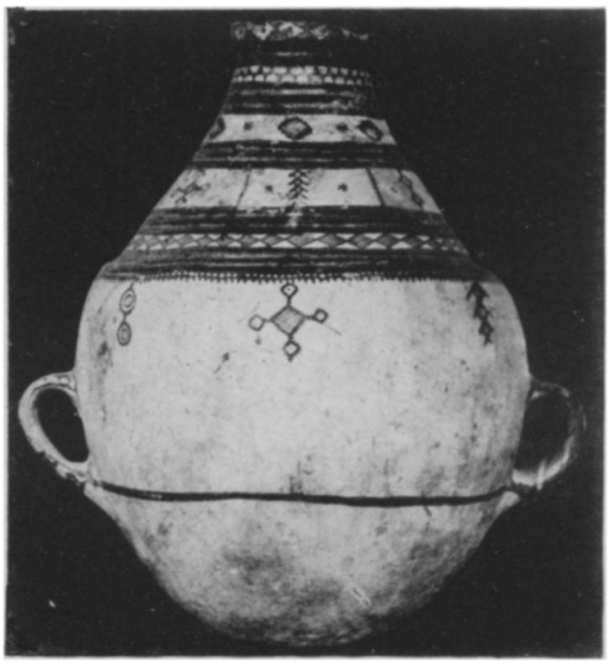

20

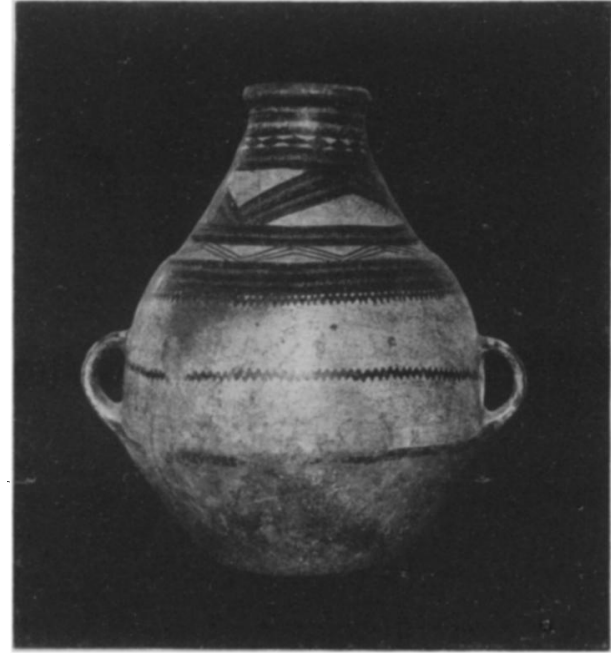

17

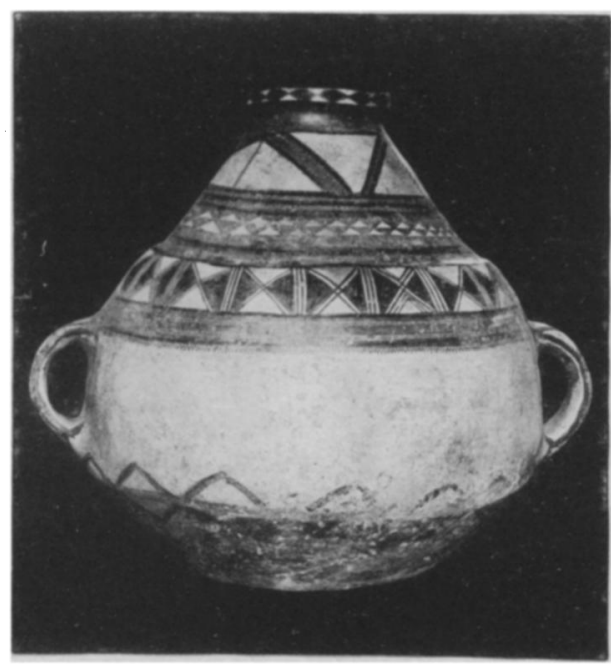

19

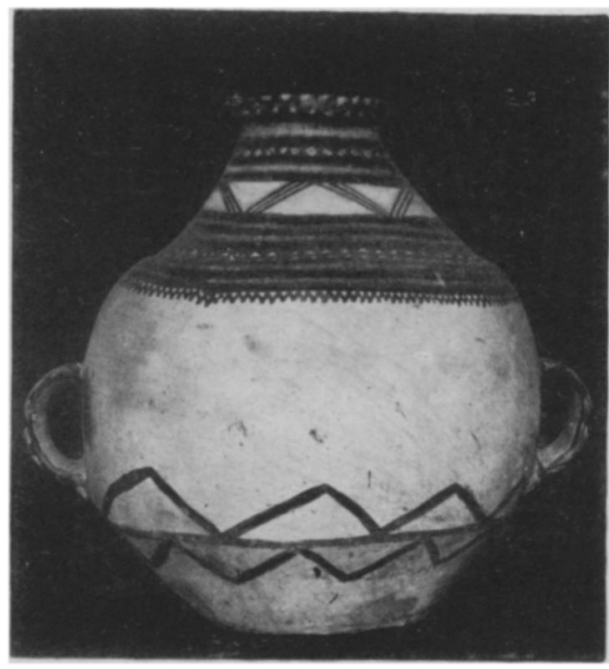

21

KABYLE POTTERY. 
various combinations in which it occurs 33 is perhaps the most characteristic. In $33,34,37$ are seen some further elaborations of 50 and 33 , which, however, are mere reduplications of the same essential elements without the addition of anything novel. Very often such patterns as 33, 34 are carried one stage further by the addition of oblique lines to the small lozenges at the two sides ( $c f$. the ornament of Pl. XVIII, 13). The latter then present much the appearance of lizard claws (35c), and the pattern might easily be supposed to be zoomorphic, but it is clearly nothing more than a development of the familiar geometrical form.

The pattern shown in 53 is interesting as it explains what would otherwise be a perplexing peculiarity in $\mathrm{Pl}$. XIX, 20, viz., the occurrence on the body of the vase of what seem to be two circles connected by a vertical line (54). I have elsewhere remarked that the circle and the spiral are never found among the designs painted upon Kabyle pottery. And this pattern on Pl. XIX, 20, affords no exception to the rule, for what look like circular rings prove on a close examination to be very carelessly drawn lozenges of the same type as those which appear at the four corners of 53. Here then we may observe the first step towards the development of the circle as an ornamental motive; but native Kabyle designers probably never, advanced any further. ${ }^{1}$ It is only on Tuareg skin vessels, so far as I am aware, that the spiral is found.

(3) The band, either vertical or horizontal, needs no special illustration. Such large pots as Pl. XIX, 17-21, show its use on wide surfaces, cf. Pl. XX passim. Where the black zones are broad they are often separated by the thin scrabbled line, 17, which has been shown to have originated from the pattern seen in 26 . The broad black zones were applied first, and sometimes so little space was left between them that there was hardly room even for a wavy line; so that in the last resort the pattern derived from the triangles is reduced to little more than a succession of pinhead dots.

The existence in our own time of this pottery with its unquestionable pedigree of full 2,500 years is from more than one point of view a circumstance of the highest interest. On the one hand, whether the manufacture originated in Cyprus or in North Africa, it proves a close commercial intercourse between the two countries at a period not later than 600 B.c. On the other hand it affords yet another welcome example of the persistence of an art unchanged and unimproved for an almost incredible length of time. Just as the punctuated or incised black ware of the Mediterranean occurs in Egypt in pre-dynastic times and is found again in the period from the XIIth to the XVIIIth dynasty, and just as the black-topped red-ware of the earliest chalcolithic Egyptians reappears in the middle Kingdom, so a technique that was invented nearly 3,000 years ago in Cyprus or in Libya is represented at the present day by the pottery of the Algerian Kabyles.

1 [The same development is traceable in the incised ornamentation of the earlier Bronze Age in Cyprus : see Ohnefalsch-Richter, Kypros, Plate ccxvi, 3, 4, 5, 7, 10, 11, 12, 14, 32 and a good series of specimens in the Ashmolean Museum, Oxford. For Sicilian Neolithic parallels see B.P.It., XVI, Pl. vi, 22 : viii, 1, 4, 9, 14.--J. L. M.] 